\title{
Volumetric mass transfer coefficients characterising VOC absorption in water/silicone oil mixtures
}

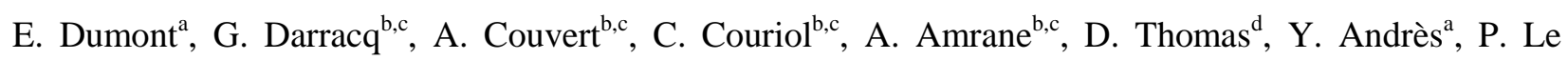
Cloirec $^{\text {b,c }}$

${ }^{a}$ UMR CNRS 6144 GEPEA, L’UNAM, École des Mines de Nantes, La Chantrerie, 4 rue Alfred Kastler, B.P. 20722, 44307 Nantes Cedex 3, France.

b École Nationale Supérieure de Chimie de Rennes, CNRS UMR 6226, Av. du Général Leclerc, CS 50837, 35708 Rennes Cedex 7, France.

${ }^{c}$ Université Européenne de Bretagne, France.

${ }^{\mathrm{d}}$ Faculté Polytechnique - Université de Mons, 9 rue de Houdain, B-7000 Mons, Belgium.

Corresponding author:

Eric Dumont (eric.dumont@mines-nantes.fr)

Tel: +33(0)2 51858266

Fax: +33(0)2 51858299

Ecole des Mines de Nantes, La Chantrerie, 4 rue Alfred Kastler, B.P. 20722, 44307 Nantes Cedex 3, France. 
Abstract

The physical absorption of three Volatile Organic Compounds (dimethyldisulphide (DMDS), dimethylsulphide (DMS) and toluene) in "water/silicone oil" systems at a constant flow rate for mixtures of different compositions $(\phi=0,5,10,15,20$ and 100\%) was investigated using a dynamic absorption method. The results indicate that silicone oil addition leads to a dramatic decrease in $\mathrm{K}_{\mathrm{L}}$ a which can be related to the change in the partition coefficient $\left(\mathrm{H}_{\text {mix }}\right)$. They confirm the results obtained for styrene absorption using another measurement technique [15]. The interpretation of the results using dimensionless ratios $\mathrm{K}_{\mathrm{L}} \mathrm{a}_{(\phi)} / \mathrm{K}_{\mathrm{L}} \mathrm{a}_{(\phi=0 \%)}$ and $\mathrm{K}_{\mathrm{L}} \mathrm{a}_{(\phi)} / \mathrm{K}_{\mathrm{L}} \mathrm{a}_{(\phi=100 \%)}$ versus $\phi$ also confirms the importance of the partition coefficient ratio $m_{R}=H_{w a t e r} / H_{o i l}$ in the $K_{L} a$ change. Moreover, the results obtained for toluene absorption in "air/water/silicone oil" systems $(\phi=10,15$ and $20 \%)$ suggest that the mass transfer pathway is in the order gas $\rightarrow$ water $\rightarrow$ oil for these operating conditions.

\section{Key-words}

Absorption; Mass Transfer; Hydrophobic VOC; TPPB; Silicone oil 


\section{Nomenclature}

a: specific gas/liquid interfacial area $\left(\mathrm{m}^{2} \cdot \mathrm{m}^{-3}\right)$

C: concentration $\left(\mathrm{g} \cdot \mathrm{m}^{-3}\right)$

D: diffusion coefficient $\left(\mathrm{m}^{2} \cdot \mathrm{s}^{-1}\right)$

$\mathrm{H}$ : dimensional form of the partition coefficient $\left(\mathrm{Pa} \cdot \mathrm{m}^{3} \cdot \mathrm{mol}^{-1}\right)$

$\mathrm{k}$ : local mass transfer coefficient $\left(\mathrm{m} . \mathrm{s}^{-1}\right)$

$\mathrm{K}$ : mass transfer coefficient $\left(\mathrm{m} . \mathrm{s}^{-1}\right)$

$\mathrm{K}_{\mathrm{L}} \mathrm{a}$ : volumetric mass transfer coefficient $\left(\mathrm{s}^{-1}\right)$

$\mathrm{m}_{\mathrm{R}}$ : ratio of partition coefficients $=\mathrm{H}_{\text {water }} / \mathrm{H}_{\mathrm{oil}}(-)$

$\mathrm{P}_{\mathrm{VOC}}$ : dimensionless form of the partition coefficient (-)

$\mathrm{R}$ : ideal gas constant $\left(8.314 \mathrm{~J} \cdot \mathrm{mol}^{-1} \cdot \mathrm{K}^{-1}\right)$

$\mathrm{T}$ : temperature $(\mathrm{K})$

$\mathrm{t}$ : time (s)

$\mathrm{V}$ : volume $\left(\mathrm{m}^{3}\right)$

\section{Greek letters}

$\phi$ : silicone oil volume fraction (-)

$\eta$ : dynamic viscosity (Pa.s)

$\tau$ : time constant (s)

\section{Superscripts}

G: gas phase

L: liquid phase

\section{Subscripts}

eq: equilibrium

G: gas phase

L: liquid phase

mix: relative to water/silicone oil mixture

oil: relative to silicone oil

water: relative to water

$\phi$ : relative to silicone oil volume fraction 


\section{Introduction}

Two-Phase Partitioning Bioreactors (TPPBs) have been identified as one of the potential biotechnologies to treat hydrophobic Volatile Organic Compounds (VOCs; [1-4]). In such gasliquid-liquid processes, the mass transfer coefficient $\mathrm{K}_{\mathrm{L}} \mathrm{a}$ is a key parameter in estimating reactor performance [5-11]. The mass transfer mechanism depends upon the dynamics of the system in which it occurs [12] but, in the case of TPPBs, the $\mathrm{K}_{\mathrm{L}}$ a change due to the addition of a nonaqueous phase (NAP) to the aqueous phase seems difficult to predict. By so doing, an extensive review devoted to oxygen transfer in hydrocarbon-aqueous dispersions [13] has highlighted the need to address the complexities of the volumetric mass transfer coefficient in TPPBs. Moreover, methods for mass transfer measurement must be carefully considered. For instance, by comparing both methods (the pressure step procedure and the gassing out procedure) for the determination of the volumetric oxygen transfer coefficient in hydrocarbon-aqueous dispersions, Correia and Clarke [9] found that the $\mathrm{K}_{\mathrm{L}} \mathrm{a}$ values obtained from these procedures diverged progressively according to the operating conditions (agitation rates and NAP volumetric fractions). In the same way, studying the volumetric oxygen transfer coefficient in water/silicone oil mixtures, Quijano et al. [10] reported that errors in $\mathrm{K}_{\mathrm{L}}$ a measurements could be due to failures in the fundamental assumption that the liquid mixture can be considered a homogeneous liquid phase (it must be stressed that perfect mixing conditions are also a critical assumption for determining the $\mathrm{K}_{\mathrm{L}} \mathrm{a}$ in gas liquid systems). Nonetheless, recent studies have pointed out the importance of the value of the partition coefficient of the liquid mixture $\left(\mathrm{H}_{\text {mix }}\right)$ in $\mathrm{K}_{\mathrm{L}}$ a determination (the liquid mixture being assumed to be a homogeneous phase [14-15]). For instance, studying the dynamic absorption of styrene in water/silicone oil mixtures, Dumont and Andrès [15] observed a dramatic decrease in the $\mathrm{K}_{\mathrm{L}} \mathrm{a}$ with increasing silicone oil volume fraction in relation to the 
decrease in the value of the partition coefficient $\mathrm{H}_{\text {mix }}$. This study highlighted that the $\mathrm{K}_{\mathrm{L}} \mathrm{a}$, which depends on numerous parameters including liquid phase properties, reactor geometry and operating conditions (Fig. 1), can be significantly influenced by the value of a thermodynamic parameter such as the partition coefficient. As accurate mass transfer evaluation remains a key issue for the development of biotechniques for VOC treatment, this work proposes to confirm the results reported in [15] for other VOCs by using another measurement technique. Thus, the $\mathrm{K}_{\mathrm{L}} \mathrm{a}$ determination was carried out for three different pollutants (i.e. dimethyldisulphide (DMDS), dimethylsulphide (DMS) and toluene) using a methodology described in [8].

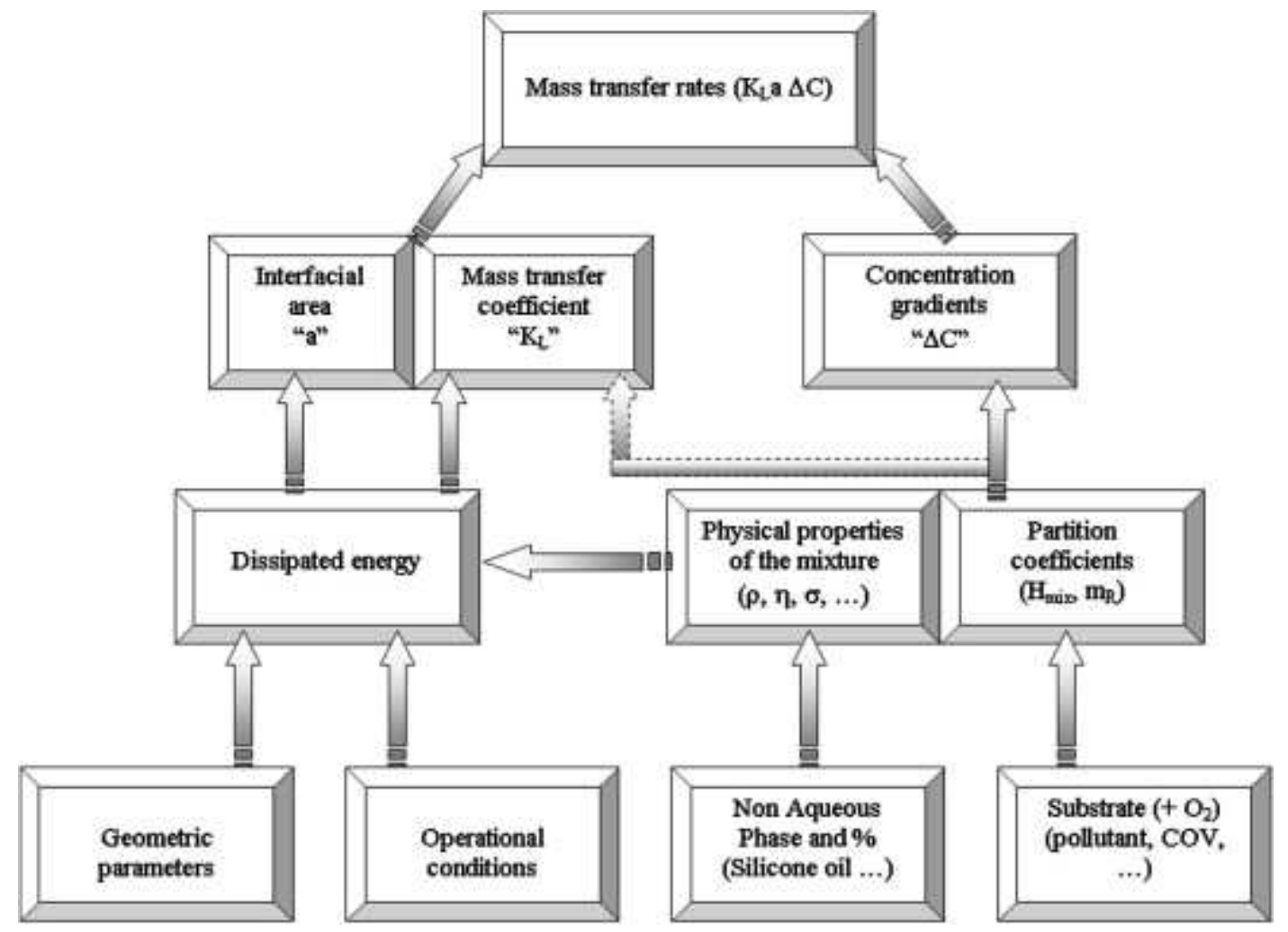

Figure 1 Dependence of mass transfer rate and volumetric mass transfer coefficient on operating parameters in a TPPB. 


\section{Materials and methods}

With the aim of treating hydrophobic VOCs in a TPPB, the volumetric mass transfer coefficients $\left(\mathrm{K}_{\mathrm{L}} \mathrm{a}\right)$ of DMDS, DMS and toluene were measured in tap water $(\phi=0 \%)$, silicone oil $(\phi=100 \%)$, and water/silicone oil mixtures of varying composition $(\phi=5,10,15$ and $20 \% \mathrm{v} / \mathrm{v})$. These compositions were chosen because: (i) water and silicone oil can be used as references; (ii) in the case where pollutant transfer and silicone oil regeneration can take place in the same compartment (stirred tank reactors, biofilters or biotrickling filters), the volumetric fraction of the organic phase must be as small as possible because the biomass is supported by the aqueous phase; however, it must be pointed out that degradation performances present an optimum silicone volume ratio of around 25\% [16]; (iii) in the case where the mass transfer of the pollutant and its degradation can occur in separate units (bioscrubbers), it is preferable to use silicone oil ( $\phi$ $=100 \%$ ) for the mass transfer of VOCs having a coefficient $m_{R}>20$ in order to reduce operating costs [17-18].

\subsection{Chemical products}

Silicone oil (dimethylpolysiloxane), Rhodorsil® Fluid 47V5, with a viscosity of $5 \mathrm{mPa} . \mathrm{s}$ was purchased from the Bluestar Silicones Company, France (density: $930 \mathrm{~kg} / \mathrm{m}^{3}$; molecular weight: $740 \mathrm{~g} / \mathrm{mol})$.

Dimethylsulphide (DMS: $\mathrm{CH}_{3}-\mathrm{S}-\mathrm{CH}_{3}$ ) and dimethyldisulphide (DMDS: $\mathrm{CH}_{3}-\mathrm{S}-\mathrm{S}-\mathrm{CH}_{3}$ ) were chosen as sulphur target pollutants due to their known malodorous character and their slight solubility in water. Toluene $\left(\mathrm{C}_{7} \mathrm{H}_{8}\right)$ was also chosen because it is a highly hydrophobic, widely used compound. Table 1 presents the physical data of the three selected pollutants and the significant values of the partition coefficients measured experimentally [14]. 
DMDS

Molecular weight $\left(\mathrm{g} \mathrm{mol}^{-1}\right) 94.2$

Density $\left(\mathrm{kg} \mathrm{m}^{-3}\right)$

$T_{\mathrm{bp}}\left({ }^{\circ} \mathrm{C}\right)$

$P_{\text {sat }}(\mathrm{Pa})$

$H_{\text {water }}\left(\mathrm{Pa} \mathrm{m}^{3} \mathrm{~mol}^{-1}\right)$

$H_{\text {oil }}\left(\mathrm{Pa} \mathrm{m}^{3} \mathrm{~mol}^{-1}\right)$

$m_{R}=H_{\text {water }} / H_{\text {oil }}(-)$

$D_{\text {water }}\left(\mathrm{m}^{2} \mathrm{~s}^{-1}\right)$

$D_{\text {oil }}\left(\mathrm{m}^{2} \mathrm{~s}^{-1}\right)$
DMS

62.1

850

37.3

53200

182.1

17.7

10
92.1

870

111

3800

680.0

2.3

296

$1.09 \times 10^{-9}[20] 1.34 \times 10^{-9}[19] 0.85 \times 10^{-9}[25] T=293 \mathrm{~K}$

$8.72 \times 10^{-11}[21]-$

$5.65 \times 10^{-10}[21]$

Table 1 Main physico-chemical properties of the three VOCs $(T=298 \mathrm{~K})$.

\subsection{Theory}

A dynamic absorption method was used to determine the volumetric mass transfer coefficients of VOCs. The experimental procedure is described in [14]. In this method, the experiments are carried out batchwise with respect to both phases (gas and water/silicone oil mixture). A schematic overview of the experimental set-up used is given in Fig. 2. At $t=0$, the liquid was VOC-free. A known gas volume loaded with a VOC was then continuously flowed through the liquid and the decrease in the VOC concentration in the gas phase was measured over time. Assuming ideal mixing in the gas and the liquid phases, the transient VOC absorption rate in the liquid phase, assumed to react as a homogeneous phase, is given by: 
$-V_{G} \frac{d C_{t}^{G}}{d t}=K_{L} a V_{L}\left(\frac{C_{e q}^{G}}{P_{V O C}}-C_{t}^{L}\right)$

where $\mathrm{P}_{\mathrm{VOC}}$ is the dimensionless concentration ratio:

$P_{V O C}=\frac{C_{e q}^{G}}{C_{e q}^{L}}$

An alternative dimensional form (in Pa. $\mathrm{m}^{3} \cdot \mathrm{mol}^{-1}$ ) of the partition coefficient generally used in this paper is:

$H=R T P_{V O C}$

According to the conservation of mass:

$V_{G} C_{t=0}^{G}+V_{L} C_{t=0}^{L}=V_{G} C_{t}^{G}+V_{L} C_{t}^{L}$

As the liquid is VOC-free at $t=0$, Eq. (4) gives:

$C_{t}^{L}=\frac{V_{G}}{V_{L}}\left(C_{t=0}^{G}-C_{t}^{G}\right)$

and

$C_{t \rightarrow \infty}^{G}=C_{e q}^{G}=\frac{H V_{G}}{R T V_{L}+H V_{G}} C_{t=0}^{G}$

A combination of Eqs. $(1,3,5$, and 6$)$ leads to (after integration between $t=0$ and $t)$ :

$\ln \left[\frac{C_{t}^{G}-C_{t \rightarrow \infty}^{G}}{C_{t=0}^{G}-C_{t \rightarrow \infty}^{G}}\right]=-K_{L} a t$

By plotting the left member of Eq. (7) versus time, a straight line is obtained whose slope gives the volumetric mass transfer coefficient $\mathrm{K}_{\mathrm{L}} \mathrm{a}$.

Considering that experiments were carried out batchwise with respect to both phases (gas and water/silicone oil mixture), it appears that Eq. (1) is a first-order linear ordinary differential equation whose analytical solution is derived from Eq. (7): 


$$
C_{t}^{G}=C_{t \rightarrow \infty}^{G}+\left(C_{t=0}^{G}-C_{t \rightarrow \infty}^{G}\right) \exp (-t / \tau)
$$

where $\tau$ is the time constant of the system corresponding to $1 / \mathrm{K}_{\mathrm{L}}$ a. The time constant represents the time needed for the system to reach $63.2 \%$ of the final (asymptotic) value. Eq. (8) shows that the system will be at equilibrium when the exponential term vanishes, and it is usually assumed that equilibrium is reached at $\mathrm{t}=3 \tau$ (i.e. $95 \%$ of $C_{t=0}^{G}-C_{t \rightarrow \infty}^{G}$ ).

In Eq. (6), the value of the VOC partition coefficient between the gas phase and the liquid mixture is given by the following equation, in agreement with the experimental measurements reported in [14]:

$H=H_{\text {mix }}=\left[\frac{1-\phi}{H_{\text {water }}}+\frac{\phi}{H_{\text {oil }}}\right]^{-1}$

In this paper, the general term "partition coefficient" is used to characterize the partition of a substance (DMS, DMDS and toluene) between the air and the absorbing liquid (mixture). In the case where water is the absorbing liquid, the term "Henry's law constant" can be used.

\subsection{Experimental procedure}

The experimental set-up implemented for pollutant absorption is presented in Fig. 2. For the preparation of waste air, pollutant was directly injected into the tank with a syringe and a continuous circulation of the laden air in a closed loop enabled the gas phase to mix thoroughly (dashed envelope in Fig. 2). The VOC concentration was continuously measured in the tank using a Flame Ionisation Detector (Cambustion HFR 400 FFID) calibrated from standards before each experiment. The response time of the analyser was less than the mass transfer response time

of the system $\left(1 / \mathrm{K}_{\mathrm{L}} \mathrm{a}\right)$. After confirming that the VOC concentration was constant, three-way diverting valves were simultaneously hand-operated in order to flow the polluted gas through the 
liquid mixture (gas flow rate: $1 \mathrm{~m}^{3} / \mathrm{h} ; \mathrm{T}=298 \mathrm{~K}$ ). The pressure changes in the gas circuit and the decrease in the VOC concentration in the gas phase were monitored and recorded as a function of time for analysis. During absorption, the mass balance of the pollutant between the gas and liquid phases was used to calculate the VOC concentration in the water/silicone oil mixture according to Eq. (5). Each experiment was repeated at least three times for the silicone oil volume fractions: $\phi$ $=0 \%, 5 \%, 10 \%$; twice for $\phi=15 \%$ and $20 \%$ and once for $\phi=100 \%$.

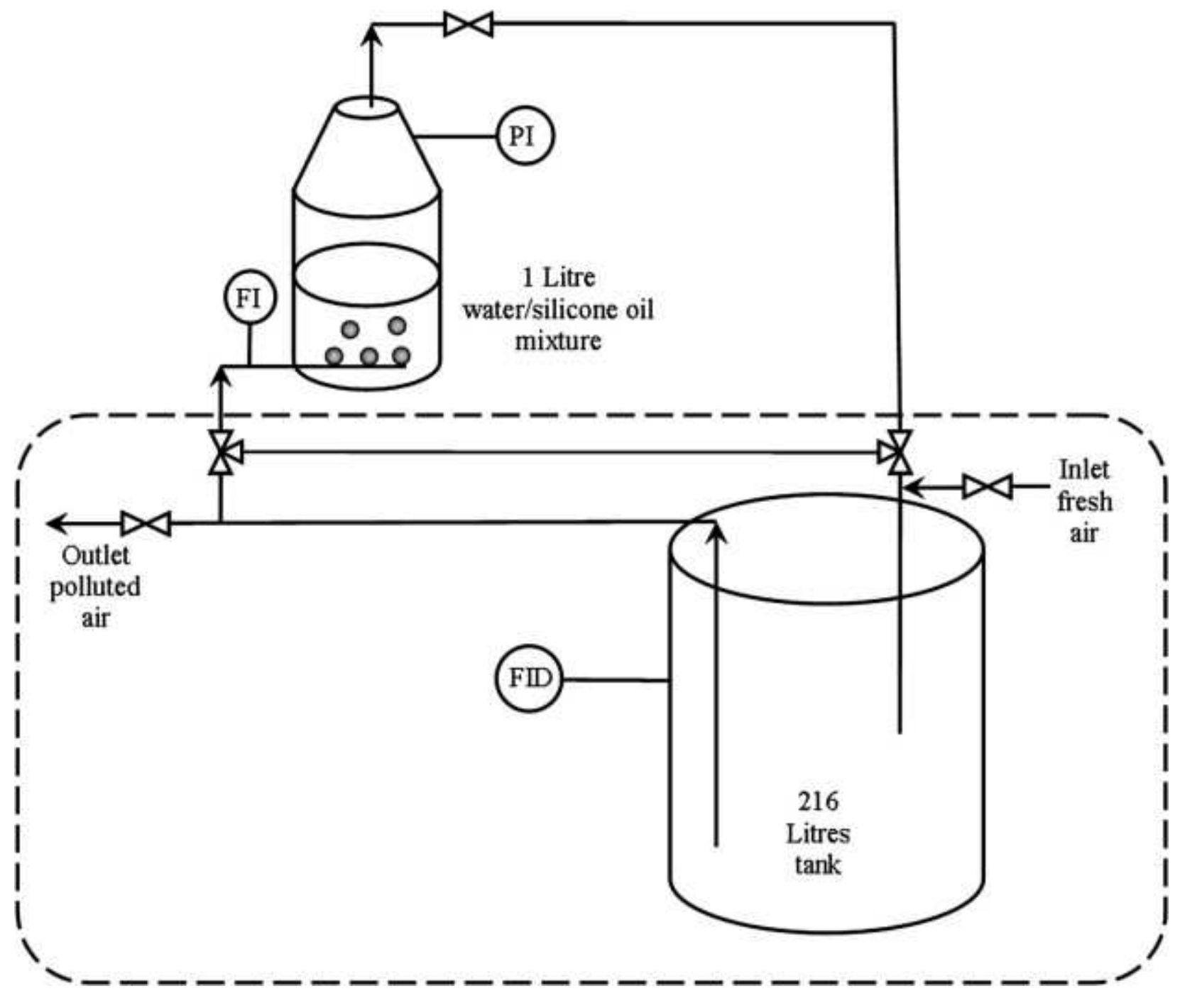

Figure 2 Schematic overview of the experimental set-up used to determine $K_{L} a$ during VOC absorption. 


\section{Results and discussion}

$\mathrm{K}_{\mathrm{L}} \mathrm{a}$ values were obtained by applying Eq. (7) to the experimental data (Fig. 3). Once determined, the corresponding time constant $\tau=1 / \mathrm{K}_{\mathrm{L}}$ a was calculated in order to compare the experimental data with the model corresponding to Eq. (8). From Fig. 4, it can be observed that the decrease in the DMDS concentration in the gas phase versus time is well described by Eq. (8) for $\phi=0 \%$, $5 \%, 10 \%$ and $15 \%$. However, for $\phi=100 \%$, the experimental points and the model began to diverge at $\mathrm{t} / \tau>2$ whereas for $\phi=20 \%$, the divergence appeared at $t / \tau<1$. These results can be explained by the continuous gas flow in the mixture causing a stripping of the pollutant. Consequently, the pollutant concentration was lower in the liquid phase and higher in the gas phase than expected. In other words, at equilibrium, the pollutant concentration in the gas phase $C_{e q}^{G}$ was higher than the expected value $C_{t \rightarrow \infty}^{G}$ given by Eq. (6). This explanation was largely developed and commented on [14] and the reader should refer to this paper for complete information. Nonetheless, the following points must be emphasised:

(i) In spite of the presence of $C_{t \rightarrow \infty}^{G}$ in Eq. (7), this equation can be used for $\mathrm{K}_{\mathrm{L}}$ a determination because linear regressions are applied only on the first points of experiments. Moreover, an alternative form of Eq. (7) can be used by introducing the expression of $C_{t \rightarrow \infty}^{G}$ (Eq. 6) into

Eq. (7). In this way, $\mathrm{K}_{\mathrm{L}} \mathrm{a}$ is determined knowing only $\mathrm{H}_{\mathrm{mix}}, C_{t=0}^{G}$ and $C_{t}^{G}$ according to the following equation:

$$
\ln \left[-\frac{H_{m i x} V_{G}}{R T V_{L}}+\frac{R T V_{L}+H_{m i x} V_{G}}{R T V_{L}} \frac{C_{t}^{G}}{C_{t=0}^{G}}\right]=-K_{L} a t
$$

No difference was observed between $\mathrm{K}_{\mathrm{L}}$ a values obtained from Eqs. (7) and (10).

(ii) For experiments where Eq. (8) satisfactorily described the experimental points for $t / \tau>1$ (i.e. for all DMDS experiments except $\phi=20 \%$ ), it can be concluded that the time constant 
$\tau$ characterised the system very well (in some cases, discrepancies between the experimental points and the model were observed for $t / \tau>3$ ). In other words, there is no doubt about the $\mathrm{K}_{\mathrm{L}}$ a values.

(iii) For experiments where experimental points were not satisfactorily described by Eq. (8) for $\mathrm{t} / \tau<1$, it must be concluded that $\tau$ values (i.e. $\mathrm{K}_{\mathrm{L}}$ a values) should be either viewed with some degree of reservation (as for DMDS corresponding to $\phi=20 \%$ ), or not considered.

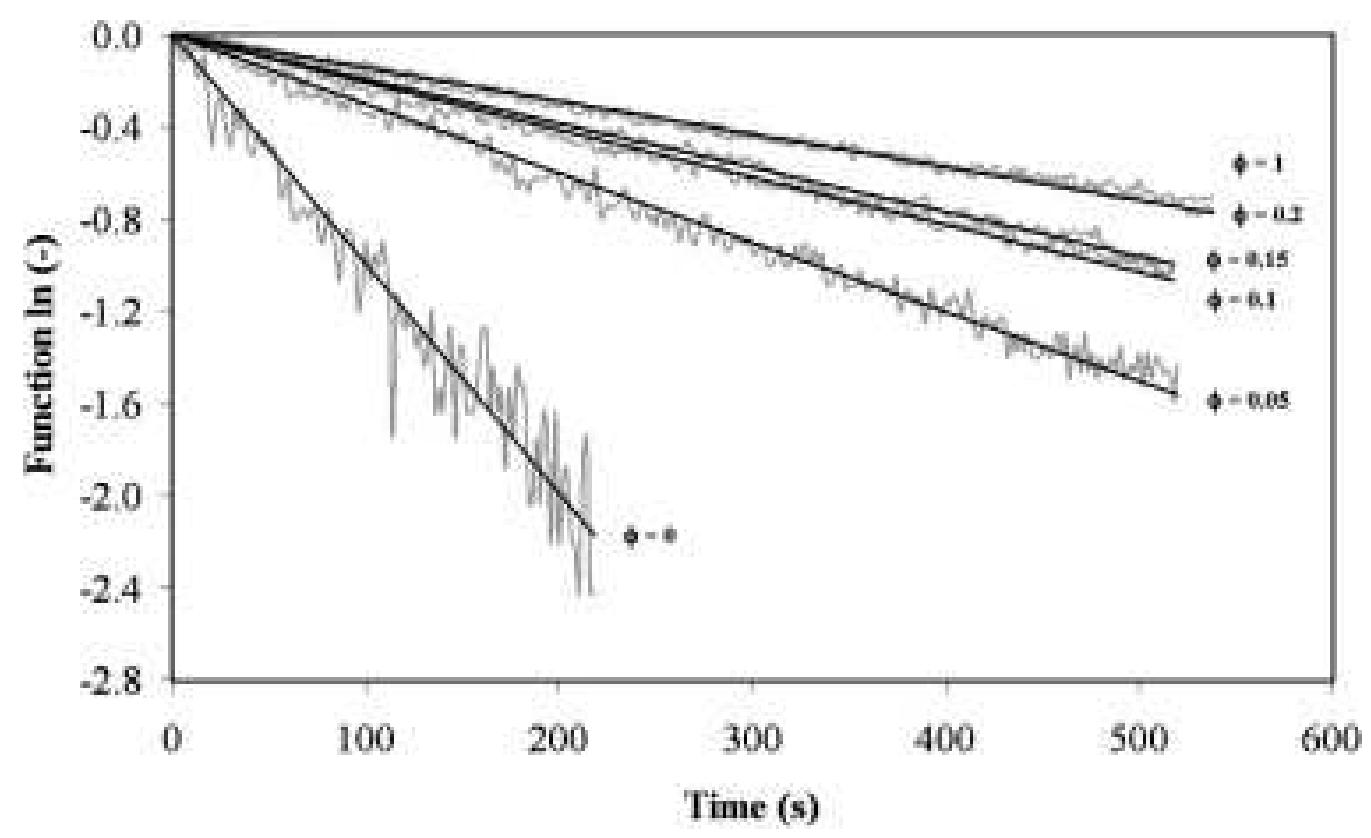

Figure 3 Examples of $K_{L} a$ determination according to Eq. (7) in the case of DMDS. Grey line: experimental points; black line: linear regression. Note that the same linear regression was obtained for $\phi=20 \%$ and $100 \%$. 


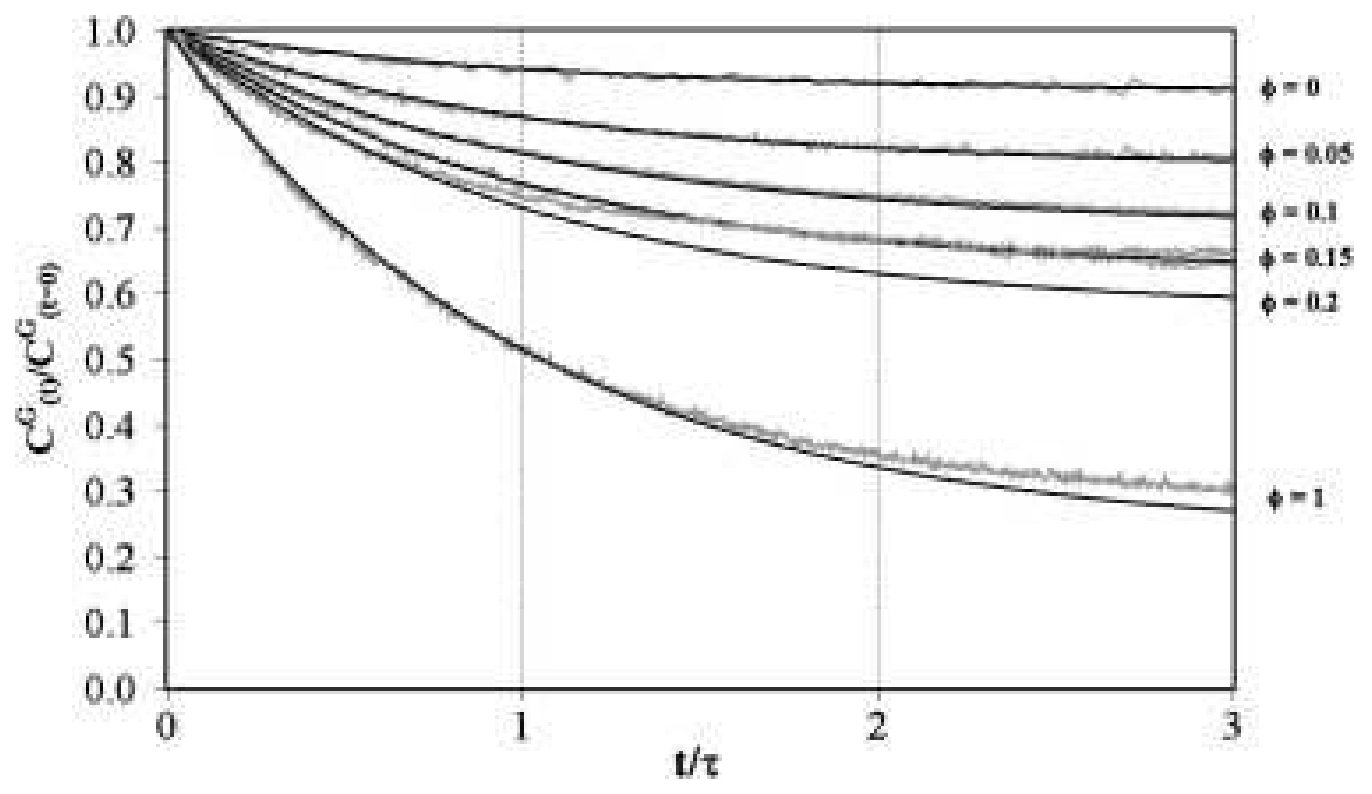

Figure 4 Transient change in the dimensionless pollutant concentration. Validation of the time constant for the different water/silicone oil mixtures in the case of DMDS. Grey line: monitored decrease in DMDS in the gas phase relative to the initial concentration; black line: model corresponding to Eq. (8)/

$$
C_{i=0}^{G}
$$

Figure 5 presents the $K_{L}$ a values which described the experimental points satisfactorily for $t / \tau>1$ according to Eq. (8). From this figure, it can be observed that silicone oil addition leads to a dramatic decrease in $\mathrm{K}_{\mathrm{L}}$ a. This result is consistent with those obtained with styrene [15] and confirms that the $\mathrm{K}_{\mathrm{L}}$ a decrease can be related to the change in the partition coefficient $\left(\mathrm{H}_{\mathrm{mix}}\right.$; see Table 2) as highlighted in Fig. 6. As observed in both these figures, the results obtained for $\phi=$ $100 \%$ must be distinguished from those obtained for $\phi$ ranging from 0 to $20 \%$. In fact, for $\phi \leq$ $20 \%$, water represents the continuous liquid phase (droplets of silicone oil being dispersed in water) whereas for $\phi=100 \%$, the continuous liquid phase is silicone oil. The following comments can be made from the experimental results: 


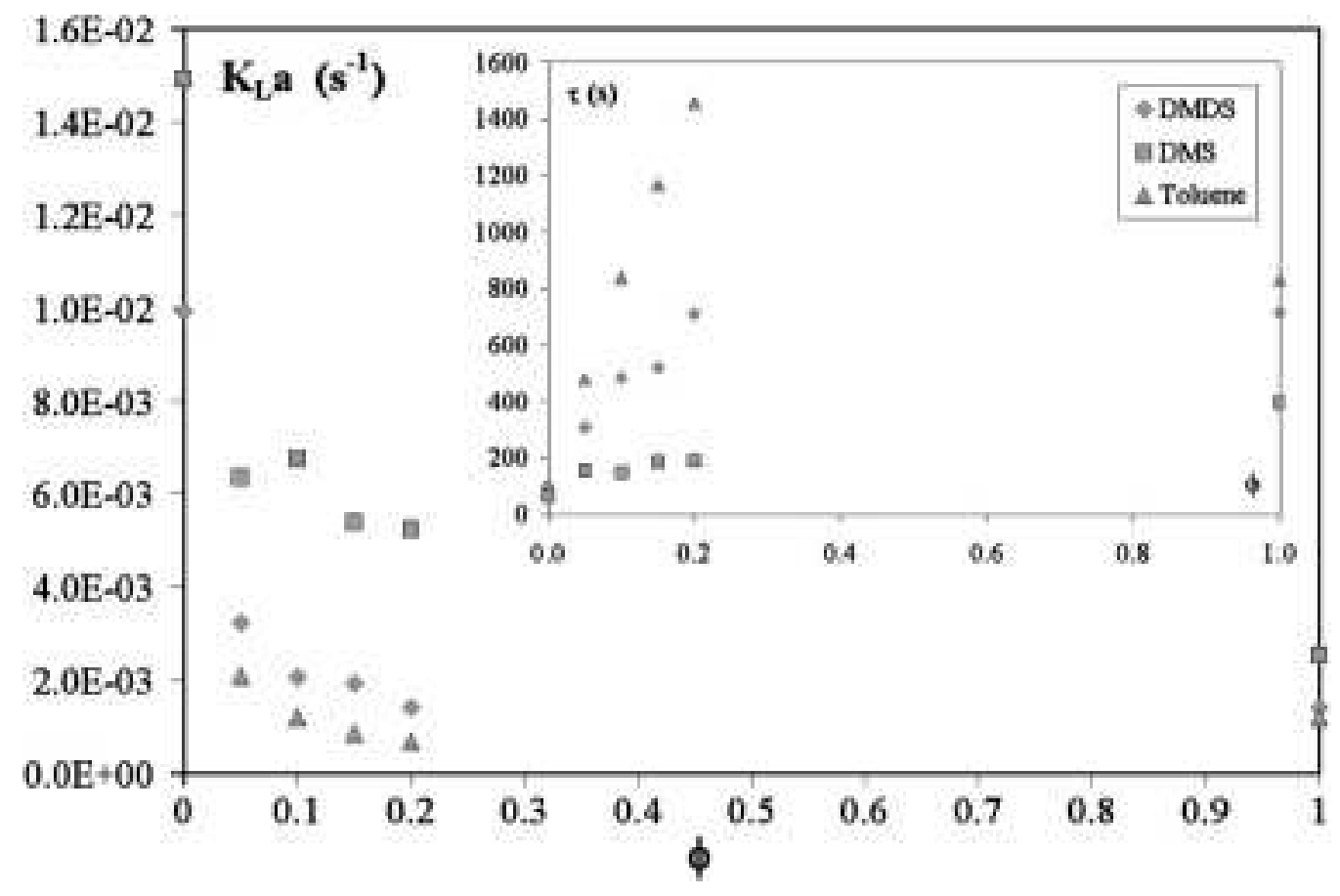

Figure 5 Change in $K_{L} a$ versus silicone oil volume fraction $\left(K_{L} a\right.$ value for toluene corresponding to $\phi=0 \%$ was not determined). Insert: change in $\tau$ versus silicone oil volume fraction.

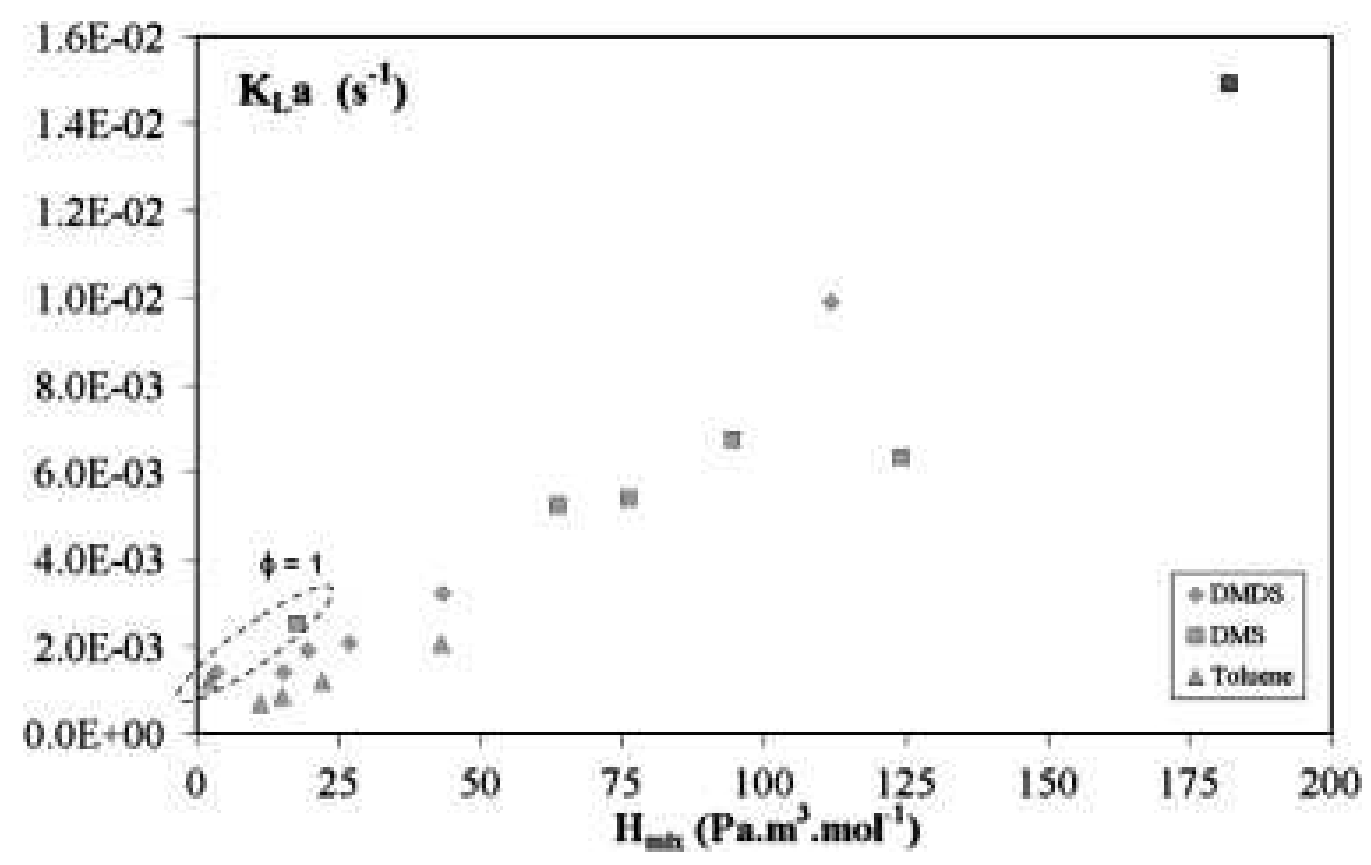

Figure 6 Change in $K_{L} a$ versus partition coefficient value. 


\begin{tabular}{|c|c|c|}
\hline & \multicolumn{2}{|c|}{$H_{\text {mix }}\left(\mathrm{Pa} \mathrm{m}^{3} \mathrm{~mol}^{-1}\right)$} \\
\hline & DMDS & DMS Toluene \\
\hline 0 & 111.9 & 182.1680 .0 \\
\hline 0.0 & 43.4 & 124.343 .2 \\
\hline 0.1 & 26.9 & $94.4 \quad 22.3$ \\
\hline 0.1 & 19.5 & $76.1 \quad 15.0$ \\
\hline 0.2 & 15.3 & $63.7 \quad 11.3$ \\
\hline 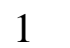 & 3.4 & $\begin{array}{ll}17.7 & 2.3\end{array}$ \\
\hline
\end{tabular}

Table $2 H_{\text {mix }}$ values according to silicone oil volume fraction $(T=298 \mathrm{~K})$.

(i) For $\phi=0 \%, \mathrm{~K}_{\mathrm{L}}$ a values were equal to $14.910^{-3}$ and $9.9910^{-3} \mathrm{~s}^{-1}$ for DMS and DMDS, respectively, i.e. $\left(\mathrm{K}_{\mathrm{L}} \mathrm{a}_{\mathrm{DMS}} / \mathrm{K}_{\mathrm{L}} \mathrm{a}_{\mathrm{DMDS}}\right)_{\phi=0}=1.5\left(\mathrm{~K}_{\mathrm{L}} \mathrm{a}\right.$ value for toluene was not determined; see point (ii)). As the fluid turbulence and the physico-chemical properties of water can be assumed to be the same for both VOCs, the difference between the $\mathrm{K}_{\mathrm{L}} \mathrm{a}$ values should be confirmed from consideration of the molecular diffusion coefficient values. Indeed, in the case of a scarcely soluble solute and according to the mass transfer theory, the overall mass transfer resistance is controlled by the liquid-side mass transfer (i.e. $\mathrm{K}_{\mathrm{L}} \approx \mathrm{k}_{\mathrm{L}}$ ) and $\mathrm{k}_{\mathrm{L}}$ is proportional to $\mathrm{D}^{\alpha}$ ( $\alpha$ varying according to the mass transfer model considered). There are few experimental determinations of molecular diffusion coefficients for DMS and DMDS in the literature. Nonetheless, Saltzman et al. and Pierre et al. reported $\mathrm{D}_{25^{\circ} \mathrm{C}}=1.3410^{-9} \mathrm{~m}^{2} / \mathrm{s}$ for DMS [19] and $\mathrm{D}_{25^{\circ} \mathrm{C}}=1.0910^{-9} \mathrm{~m}^{2} / \mathrm{s}$ for DMDS [20], respectively, i.e. $\left(\mathrm{D}_{\mathrm{DMS}} / \mathrm{D}_{\mathrm{DMDS}}\right)_{25^{\circ} \mathrm{C}}=1.2$ which is in agreement with the value of the $\left(\mathrm{K}_{\mathrm{L}} \mathrm{a}_{\mathrm{DMS}} / \mathrm{K}_{\mathrm{L}} \mathrm{a}_{\mathrm{DMDS}}\right)_{\phi=0}$ ratio. 
(ii) For $\phi \leq 20 \%$, the change in $\mathrm{K}_{\mathrm{L}}$ a could be attributed to the modification of the specific gas/liquid interfacial area due to silicone oil addition, as well as changes in many parameters (viscosity, diffusivity, surface tension) as illustrated in Fig. 1, but the experimental results support the idea that the decrease in $\mathrm{K}_{\mathrm{L}}$ a with silicone oil addition can be mainly attributed to the fact that hydrophobic pollutants, which are consequently scarcely soluble in water $(\phi=0 \%)$, become more and more soluble in water/silicone oil mixtures with the increase in $\phi$ (in agreement with the decrease in the $\mathrm{H}_{\text {mix }}$ value; Table 2). In this case, and according to the film theory (Eq. 11), it can be assumed that the gas film resistance $\left(\mathrm{RT} / \mathrm{Hk}_{\mathrm{G}}\right)$, considered insignificant with regard to the liquid film resistance $\left(1 / \mathrm{k}_{\mathrm{L}}\right)$ for $\phi=0 \%$, increases dramatically with oil addition leading to an increase in the volumetric mass transfer coefficient:

$$
\frac{1}{K_{L} a}=\frac{1}{k_{L} a}+\frac{R T}{H k_{G} a}
$$

Moreover, it must be pointed out that the relation between $\mathrm{K}_{\mathrm{L}} \mathrm{a}$ and $\mathrm{H}_{\text {mix }}$ (Fig. 6) for $\phi \leq 20 \%$ can also explain the difficulty of carrying out accurate measurements for toluene in water $(\phi=0 \%)$. In fact, according to Fig. $6, \mathrm{~K}_{\mathrm{L}}$ a values increase roughly linearly with $\mathrm{H}_{\text {mix }}$ whatever the VOC. As the Henry's law constant of toluene in water $\mathrm{H}_{\text {water }}$ is equal to $680 \mathrm{~Pa}^{3} \mathrm{~m}^{3} \cdot \mathrm{mol}^{-1}$, an extrapolation of the data from Fig. 6 leads to a $\mathrm{K}_{\mathrm{L}}$ a value corresponding to a time constant of the system of about $30 \mathrm{~s}$, which could represent too short a time to be accurately determined.

(iii) For $\phi=100 \%$, the $\mathrm{K}_{\mathrm{L}}$ a dependence versus $\mathrm{H}_{\mathrm{oil}}$ is clearly revealed in Figs. 5-6. As for water $(\phi=0 \%)$, the fluid turbulence and the physico-chemical properties of the silicone oil can be assumed to be the same for the three VOCs. Consequently, it could be interesting to compare the molecular diffusion coefficient values for the three VOCs. However, experimental diffusion 
coefficient values are scarce in the literature and must be considered with caution. For example, the diffusion coefficients of toluene and DMDS in the silicone oil used in this study $(\eta=5$ mPa.s) have been determined [21] (5.65 $10^{-10}$ and $8.7210^{-11} \mathrm{~m}^{2} / \mathrm{s}$ for toluene and DMDS, respectively; the value for DMS was not given) but the comparison of these values with those calculated with semi-empirical formulae indicated that they cannot be used to predict VOC diffusivity in viscous solvents [21]. Moreover, it was not possible to compare them with the literature data because no similar measurements could be found. Nonetheless, to give some idea of analogous measurements, Heymes et al. experimentally measured a diffusion coefficient of toluene in silicone oil $(\eta=20 \mathrm{mPa} . \mathrm{s})$ equal to $5.4610^{-10} \mathrm{~m}^{2} / \mathrm{s}$ [22] which is close to the value proposed in [21] while Pierre et al. reported a diffusion coefficient of DMDS in an edible oil (mix of triglycerides of the fractionated vegetable fatty acids $\mathrm{C}_{8}$ and $\mathrm{C}_{10} ; \eta=30 \mathrm{mPa} . \mathrm{s}$ ) equal to 1.1 $10^{-10} \mathrm{~m}^{2} / \mathrm{s}$ [20]. It is therefore obvious that special consideration should be given to the determination of VOC diffusion coefficients in viscous silicone oils, as well as in water/silicone oil mixtures, in future studies.

(iv) From Fig. 5, it clearly appears that the time constant $\tau$ for toluene can be higher for water/silicone oil mixtures than for pure silicone oil (in other words, $\mathrm{K}_{\mathrm{L}}$ a values can be lower for water/silicone oil mixtures than for pure silicone oil). This observation cannot be made for DMS but it can be seen that $\tau_{(\phi=20 \%)} \approx \tau_{(\phi=100 \%)}$ for DMDS (Fig. 3). Two points must be highlighted in order to explain this result. First, the addition of a small amount of silicone oil to water led to a dramatic decrease in the $\mathrm{H}_{\text {mix }}$ value which tended rapidly towards $\mathrm{H}_{\mathrm{oil}}$. As can be observed in Fig. 7 presenting the difference between $\mathrm{H}_{\text {mix }}$ and $\mathrm{H}_{\text {oil }}$ relative to $\mathrm{H}_{\text {water }}-\mathrm{H}_{\mathrm{oil}}$, this trend was more pronounced for increasing $\mathrm{m}_{\mathrm{R}}$ values. Consequently, the ability of water/silicone oil mixtures $(\phi$ 
$=10,15$ or $20 \%$ ) to absorb toluene is close to that of silicone oil to absorb it (but the amount of toluene that can be transferred is higher for silicone oil than for mixtures). The second point lies in the fact that, although $\mathrm{H}_{\text {mix }}$ values were very close to $\mathrm{H}_{\mathrm{oil}}$ values for $\phi>10 \%$, the water/silicone oil mixtures were mainly composed of water which represents the continuous liquid phase. As the time needed to reach equilibrium was longer for mixtures than for pure silicone oil, it can be concluded that the liquid mixture offers a greater resistance to the mass transfer than silicone oil. Consequently, the pathway for mass transfer could probably be in the order gas $\rightarrow$ water $\rightarrow$ oil (the silicone oil being dispersed droplets). If the mass transfer pathway was in the order gas $\rightarrow$ oil $\rightarrow$ water (the silicone oil spreading on the bubble), the liquid-side mass transfer resistance should be the same for liquid mixtures and pure silicone oil and logically $\tau$ should be lower for water/silicone oil mixtures than for pure silicone oil. This conclusion about the mass transfer pathway is in agreement with the results obtained for styrene absorption [15] which revealed that the mass transfer flux was constant whatever the silicone oil volume fraction $(\phi=2,10$ and $20 \%)$. It is also in agreement with the fact that the spreading coefficient for the water/silicone oil mixtures is negative when water and silicone oil are mutually saturated, i.e. silicone oil remains as dispersed droplets in water [23-24]. The spreading coefficient, S, of oil on water is defined as:

$S_{\text {oil/water }}=\sigma_{\text {water/G }}-\left(\sigma_{\text {oil/G }}+\sigma_{\text {oil/water }}\right)$

where $\sigma_{\mathrm{ij}}$ is the surface tension between phase $\mathrm{i}$ and $\mathrm{j}$. As defined by Eq. (12), the spreading coefficient quantifies the ability if an oil phase to either bead up (form a droplet if $S<0$ ) or spread out (form a film if $S>0$ ) when contacting the aqueous phase. To date, although the results reported in the literature were not able to lead to an accurate conclusion about the influence of this coefficient on the mass transfer pathway [5], it is assumed that the most probable mass 
transfer pathway should be in series for beading oils. Hence, in our opinion the results presented in this study give a valuable contribution to the mass transfer mechanisms which remains still disputed [13]. To summarise this interpretation of toluene absorption, it can be said that the time needed to reach equilibrium increases with $\phi$ because, on the one hand, the absorption capacity of the mixture increases with $\phi$ and, on the other hand, while water remains the continuous liquid phase, its presence is a barrier to the mass transfer.

Figures $8 \mathrm{a}$ and $\mathrm{b}$ give the change in the dimensionless ratios $\mathrm{K}_{\mathrm{L}} \mathrm{a}_{(\phi)} / \mathrm{K}_{\mathrm{L}} \mathrm{a}_{(\phi=0 \%)}$ and $\mathrm{K}_{\mathrm{L}} \mathrm{a}_{(\phi)} / \mathrm{K}_{\mathrm{L}} \mathrm{a}_{(\phi=100 \%)}$ versus $\phi$. Both figures confirm the importance of the partition coefficient ratio $m_{R}$ in the $K_{L}$ a change. Moreover, Fig. 8a confirms that the results reported in this study for DMS and DMDS follow the same trend as those obtained for styrene [15]. According to these figures, especially Fig. 8b, it seems that special attention should be devoted to the electrostatic interactions between solvent molecules (water, oil, and mixtures) and solute molecules in future studies. 


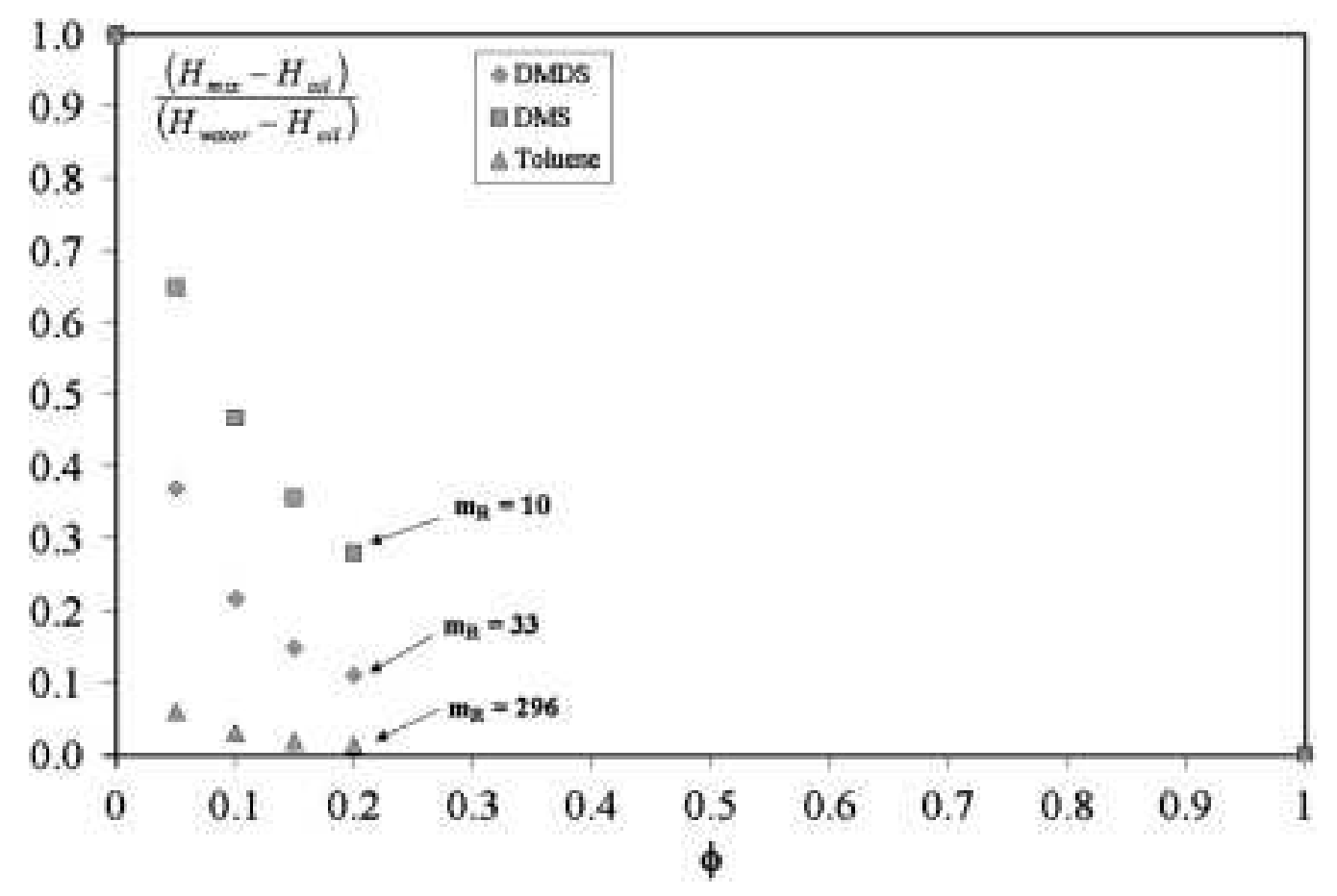

Figure 7 Ability of water/silicone oil mixtures to absorb VOCs. 

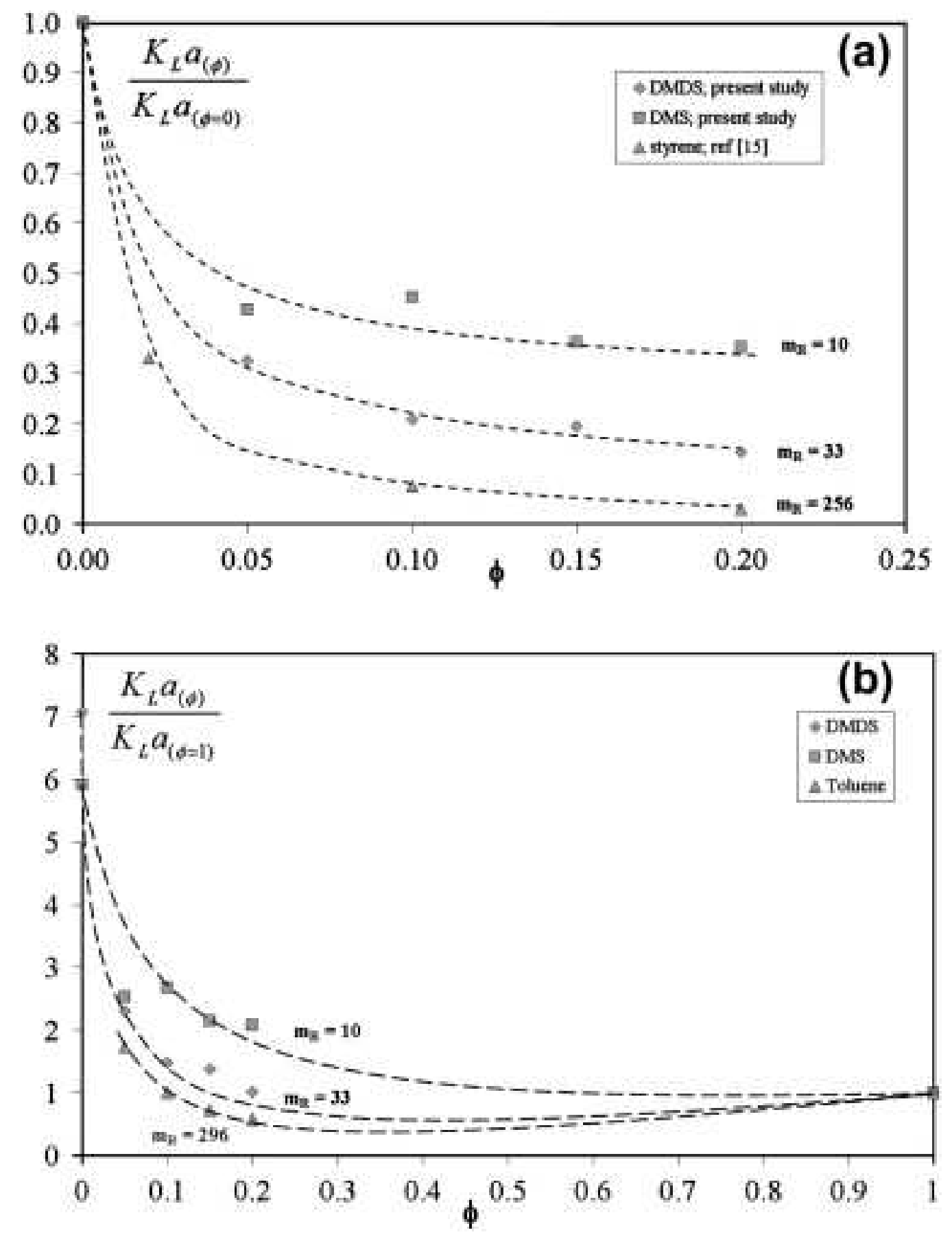

Figure $8 \boldsymbol{a}, \boldsymbol{b}$ Change in $K_{L} a$ relative to (a) $K_{L} a_{\text {water }}$ and (b) $K_{L} a_{\text {silicone oil. }}$ Note that the $K_{L} a$ value for toluene corresponding to $\phi=0 \%$ was not determined. 


\section{Conclusion}

This experimental study of the physical absorption of three hydrophobic VOCs (DMS, DMDS and toluene) in various water/silicone oil systems confirms the results previously obtained for styrene absorption. It can be concluded that silicone oil addition leads to a dramatic decrease in the $\mathrm{K}_{\mathrm{L}}$ a which is mainly related to the decrease in the $\mathrm{H}_{\text {mix }}$ value (Eq. 9), which depends on the $m_{R}$ value. Moreover, for toluene, characterised by a high $m_{R}$ value $(=296)$, the $K_{L}$ a measured for $\phi=10,15$ and $20 \%$ is lower than the overall volumetric mass transfer coefficient measured for pure silicone oil. This result can be interpreted by assuming a mass transfer pathway in the order gas $\rightarrow$ water $\rightarrow$ oil for these operating conditions. In order to complete these results, the experimental determination of VOC diffusion coefficients in viscous silicone oils, as well as in water/silicone oil mixtures, should be carried out in future studies.

\section{References}

[1] A.J. Daugulis, Two-phase partitioning bioreactors: a new technology platform for destroying xenobiotics, Trends Biotechnol. 19 (2001) 457-462.

[2] R. Muñoz, S. Villaverde, B. Guieysse, S. Revah, Two-phase partitioning bioreactors for treatment of volatile organic compounds, Biotechnology Advances 25 (2007) 410-422.

[3] C. Kennes, E.R. Rene, M.C. Veiga, Bioprocesses for air pollution control, J. Chem. Technol. Biotechnol. 84 (2009) 1419-1436.

[4] S-H. Yeom, A.J. Daugulis, D.R. Nielsen, A strategic approach for the design and operation of two-phase partitioning bioscrubbers for the treatment of volatile organic compounds, Biotechnol. Prog. 26 (2010) 1777-1786. 
[5] E. Dumont, H. Delmas, Mass transfer enhancement of gas absorption in oil-in-water systems: a review, Chem. Eng. Proc. 42 (2003) 419-438.

[6] A. Kundu, E. Dumont, A.-M. Duquenne, H. Delmas, Mass transfer characteristics in gasliquid-liquid systems, Can. J. Chem. Eng. 81 (2003)640-646.

[7] E. Dumont, Y. Andrès, P. Le Cloirec, Effect of organic solvents on oxygen mass transfer in multiphase systems: application to bioreactors in environmental protection, Biochem. Eng. J. 30 (2006) 245-252.

[8] E. Dumont, Y. Andrès, P. Le Cloirec, Mass transfer coefficients of styrene and oxygen into silicone oil emulsions in a bubble reactor, Chem. Eng. Sci. 61 (2006) 5612-5619.

[9] L.D.C. Correia, K.G. Clarke, Measurement of the overall volumetric oxygen transfer coefficient in alkane-aqueous dispersions, J. Chem. Technol. Biotechnol. 84 (2009) 17931797.

[10] G. Quijano, R. Chavez-Avila, R. Munoz, F. Thalasso, A. Ordaz, $\mathrm{K}_{\mathrm{L}}$ a measurement in twophase partitioning bioreactors: new insights on potential errors at low power input, J. Chem. Technol. Biotechnol. 85 (2010) 1407-1412.

[11] S. Kim, M.A. Deshusses, Determination of mass transfer coefficients for packing materials used in biofilters and biotrickling filters for air pollution control. 1. Experimental results, Chem. Eng. Sci. 63 (2008) 841-855.

[12] E.S Hamborg, S.R.A Kersten, G.F. Versteeg, Absorption and desorption mass transfer rates in non-reactive systems, Chem. Eng. J. 161 (2010) 191-195.

[13] K.G. Clarke, L.D.C. Correia, Oxygen transfer in hydrocarbon-aqueous dispersions and its applicability to alkane bioprocesses: a review, Biochem. Eng. J. 39 (2008) 405-429.

[14] E. Dumont, G. Darracq, A. Couvert, C. Couriol, A. Amrane, D. Thomas, Y. Andrès, P. Le Cloirec, Determination of partition coefficients of three volatile organic compounds 
(dimethylsulphide, dimethyldisulphide and toluene) in water/silicone oil mixtures, Chem. Eng. J. 162 (2010) 927-934.

[15] E. Dumont, Y. Andrès, Styrene absorption in water-silicone oil mixtures, Chem. Eng. J. 200-202 (2012) 81-90.

[16] G. Darracq, A. Couvert, C. Couriol, D. Thomas, A. Amrane, E. Dumont, Y. Andrès, P. Le Cloirec, Optimization of the volume fraction of the NAPL, silicone oil, and biodegradation kinetics of toluene and DMDS in a TPPB, Int. Biodeterioration Biodegradation, 71 (2012), 9-14.

[17] E. Dumont, G. Darracq, A. Couvert, C. Couriol, A. Amrane, D. Thomas, Y. Andrès, P. Le Cloirec, VOC absorption in a countercurrent packed-bed column using water/silicone oil mixtures: influence of silicone oil volume fraction, Chem. Eng. J. 168 (2011) 241-248.

[18] E. Dumont, G. Darracq, A. Couvert, C. Couriol, A. Amrane, D. Thomas, Y. Andrès, P. Le Cloirec, Hydrophobic VOC absorption in two-phase partitioning bioreactors; influence of silicone oil volume fraction on absorber diameter, Chem. Eng. Sci. 71 (2012) 146-152.

[19] E.S. Saltzman, D.B. King, K. Holmen, C. Leck, Experimental determination of the diffusion coefficient of dimethylsulfide in water, J. Geophysical Research 98 (1993) 1648116486.

[20] F.X. Pierre, I. Souchon, V. Athes-Dutour, M. Marin, Membrane-based solvent extraction of sulfur aroma compounds: influence of operating conditions on mass transfer coefficients in a hollow fiber contactor, Desalinisation, 148 (2002) 199-204.

[21] G. Darracq, A. Couvert, C. Couriol, A. Amrane, D. Thomas, E. Dumont, Y. Andrès, P. Le Cloirec, Silicone oil: an effective absorbent for the removal of hydrophobic volatile organic compounds, J. Chem. Technol. Biotechnol. 85 (2010) 309-313. 
[22] F. Heymes, P. Manno Demoustier, F. Charbit, J.L. Fanlo, P. Moulin, A new efficient absorption liquid to treat exhaust air loaded with toluene, Chem. Eng. J. 115 (2006) 225231.

[23] E.S. Basheva, D. Ganchev, N.D. Denkov, K. Kasuga, N. Satoh, K. Tsujii, Role of Betaine booster in the presence of silicone oil droplets, Langmuir 16 (2000) 1000-1013.

[24] E.S. Basheva, S. Stoyanov, N.D. Denkov, K. Kasuga, N. Satoh, K. Tsujii, Foam boosting by amphiphilic molecules in the presence of silicone oil, Langmuir 17 (2001) 969-979. 